\title{
Repeatability and reproducibility of Tearlab measurements
}

\author{
WDH Gillan*
}

The Anterior Eye Research Group, Department of Optometry, University of Johannesburg, PO Box 524, Auckland Park, 2006 South Africa

Received 13 August 2012; revised version accepted 26 February 2013

\begin{abstract}
It is well established that the diagnosis of dry eye is difficult. Tear osmolarity is considered by some to be the only metric of dry eye that is repeatable with some claiming that osmolarity is the best diagnostic metric for dry eye. A recently developed system, the Tearlab osmolarity system, is now available that can give a measure of tear osmolarity in less than 60 seconds. It is important that any new instrument be evaluated for its
\end{abstract}

repeatability and reproducibility. The aim of this study was to investigate the repeatability and reproducibility of the Tearlab system by taking multiple, successive measurements of osmolarity of a manufacturer supplied calibration/test solution. The results of this investigation show that the Tearlab osmolarity system provides reasonably accurate, repeatable and reproducible measurements of tear osmolarity. (S Afr Optom 2013 72(1) 19-24)

Key words: Dry eye, tear osmolarity, Tearlab osmolarity system

\section{Introduction}

Dry eye is defined as: “... a multifactorial disease of the tears and ocular surface that results in symptoms of discomfort, visual disturbance and tear film instability with potential damage to the ocular surface. It is accompanied by increased osmolarity of the tear film and inflammation of the ocular surface" . Evidence suggests that multiple factors play a role in the development of dry eye: "factors such as age, hormonal status, genetics, sex, immune status, innervation status, nutrition, pathogens and environmental stress alter the cellular and molecular structure/function of components of the ocular surface system" 2 . Several studies have shown that dry eye disease is a common disorder and is prevalent in $0.39 \%$ to approximately $34 \%$ of the general population ${ }^{3-6}$. In the past it has been estimated that 7 to 10 million people in the United States were making use of tear supplements to alleviate dry eye symptoms ${ }^{7}$.
The diagnosis of dry eye is difficult. A lack of a uniform set of criteria (a so-called "gold standard") for the diagnosis of dry eye results in difficulties ${ }^{8}$. There is poor correlation between the signs and symptoms of dry eye $e^{9-12}$. Some authors have stated that "patient symptoms influence dry eye diagnosis and grading of dry eye more than clinical test results"10. Khanal et al state: "Diagnosis of dry eye disease is made difficult by its multifactorial etiology, by the need for a comprehensive definition and by the use of tests that are limited and variable in their assessment of the tears and ocular surface" $" 11$.

It has been suggested that the measurement of tear osmolarity gives an indication of changes in tear dynamics $^{13}$ and that osmolarity of the tears might provide a useful index for the diagnosis of dry eye $\mathrm{e}^{14}$. Some authors are of the opinion that tear osmolarity is the best single test for the diagnosis of dry ey $\mathrm{e}^{11,15}$. The Tearlab osmolarity system is a relatively new instrument that "... is a tear fluid collection and testing device for 
the quantitative measurement of osmolarity of human tears..." 16 . The Tearlab system "...provides a quick and simple method of determining tear osmolarity using nanolitre volumes of tear fluid collected from the eyelid margin"16. Tear samples can be collected and analyzed in under 60 seconds. Osmolarity is recorded in milli-Osmols per litre $(\mathrm{mOsms} / \mathrm{l})^{16}$. Normal patients (non-dry eye patients) have been found to have a mean osmolarity of $302 \mathrm{mOsms} / 1$ (range: 275-316 mOsms/l) while dry eye patients have a mean of $327 \mathrm{mOsms} / \mathrm{l}^{15}$ (range: $>316 \mathrm{mOsms} / \mathrm{l}$ ). Tear hyperosmolarity, defined by Tomlinson et $a l^{15}$ as an osmolarity measure $>316 \mathrm{mOsms} / 1$, is a better indictor of dry eye than any other single test used to diagnose dry eye ${ }^{15}$. Using a hyperosmolarity cutoff measure of $312 \mathrm{mOsms} / \mathrm{l}$, Lemp et al ${ }^{17}$ have shown tear osmolarity to have a sensitivity of $73 \%$ and a specificity of $92 \%$ in the diagnosis of dry eye. Lemp et $a l^{17}$ also state: "tear osmolarity is the best single metric both to diagnose and classify dry eye disease". The Tearlab system has been used in several investigations of osmolarity. The effects of eye drops (tear supplements) on osmolarity were reported by Montani where osmolarity was reduced following the instillation and use of the eye drops ${ }^{18}$. Peral et $a l^{19}$ found osmolarity to remain stable over eight hours of wearing Biofinity contact lenses. An assessment of dry eye treatment strategies included the use of Tearlab measurements of osmolarity where it was stated: "...tear osmolarity provides the most objective, measurable test for determining improvement in dry eye patients" 20 .

It is important that an instrument, especially a relatively new one, gives reliable, repeatable and reproducible measurements. Repeatability of measurements is defined as: "closeness of the agreement between the results of successive measurements of the same measurand carried out under the same conditions of measurement" 21 . Certain conditions need to be met for the concept of repeatability to be valid namely: "the same measurement procedure, the same observer, the same instrument used under the same conditions, the same location, and, the repetition needs to be over a short period of time" ${ }^{21}$. Multiple measurements (using the same instrument and conditions) need to be repeatable with Murray and Lawrence ${ }^{22}$ stating: "tests with good repeatability are generally better than those with poor repeatability, as they give similar results when repeated on the same patient". Numerous researchers consider reproducibility to be when a series of successive measurements (for example ten successive measurements taken on one day) are repeated several days later and then analyzed ${ }^{23-25}$.

The aim of this investigation was to evaluate the repeatability and reproducibility of multiple measurements of tear osmolarity using the Tearlab system.

\section{Method}

The Tearlab system and how it works has been described in detail elsewhere ${ }^{16,20}$. What follows is a short exposition of how the Tearlab system operates. The Tearlab system consists of a base-unit that holds two collection devices. Prior to use each collection device is calibrated using an electronic check card which is attached to the collection device which is then attached to the base-unit so that a measurement can be obtained. If the measurement of the electronic check card is equivalent to that stated by the manufacturer then the device is considered to be functioning correctly. In terms of this study the measurement of the check card was $334 \mathrm{mOsms} / \mathrm{l}$. Before analyzing a sample of tears (in this instance a calibration solution) a test card is attached to the collection device and the sample ( $20 \mathrm{nl}$ of tears) is collected from the lower lid margin of the subject. The collection device is then attached to the base-unit and within several seconds a measurement of tear film osmolarity is obtained.

In this study calibration/control solutions were obtained from the manufacturer and used as tear samples. The control solution "is a quality control material used for verifying the quantitative performance of tearlab osmolarity test cards..." ${ }^{\prime 16}$. Each ampoule of control solution contains $1.0 \mathrm{ml}$ of solution, and in the case of ampoules used in this study (lot number: 90CU301), has a controlled osmolarity of $338 \mathrm{mOsms} / 1$ (expected range $\pm 15 \mathrm{mOsms} / \mathrm{l}, \mathrm{SD} \pm 3 \mathrm{mOsms} / \mathrm{l}$, as stated by the manufacturer). Ten consecutive measurements of osmolarity of the control solution were obtained using ten test cards during session one. The ampoule of control solution was then sealed and left at room temperature for approximately 24 hours when a further, second session of ten measurements of osmolarity, using ten test cards, were taken from the 
same sample solution. Again, prior to use the electronic check card was attached to the collection device and a measurement obtained. The measurement of the check card was $334 \mathrm{mOsms} / \mathrm{l}$ (equivalent to that stated by the manufacturer).

\section{Results}

Table 1 shows the results of ten measurements of osmolarity for sessions one and two.

Table 1. Tear osmolarity data collected during sessions one and two. All measurements are in mOsms/l.

\begin{tabular}{l|c|c} 
Measurement & Session one & Session two \\
\hline 1 & 336 & 334 \\
3 & 329 & 339 \\
4 & 330 & 331 \\
5 & 330 & 329 \\
6 & 328 & 338 \\
7 & 331 & 326 \\
8 & 327 & 334 \\
9 & 325 & 349 \\
10 & 327 & 335 \\
Mean & 343 & 332 \\
Standard & 330.6 & 334.7 \\
Deviation & 5.27 & 6.36 \\
95\% CI on & $327-333.63$ & $329.95-338.52$ \\
mean & & \\
Median & 329.50 & 334.00 \\
Interquartile & $327-331$ & $331-338$ \\
range & & \\
95\% CI on & $327-333.63$ & $329.95-338.53$ \\
median & & \\
& &
\end{tabular}

Figure 1 shows box and whisker plots for the data collected during sessions one and two. The mean of the data is shown as the small square within the box, the box shows one standard error on the mean above and below the mean and the whiskers indicate one standard deviation above and below the mean.



Figure 1. Box and whisker plots for data collected during sessions one and two are shown. The means, standard error on the means and the standard deviation from the means are indicated.

\section{Intra-session repeatability}

The means and standard deviations, as well as the $95 \%$ confidence intervals on the means, for the data collected during sessions one and two are indicated in Table 1. The coefficient of repeatability (defined by Bland and Altman ${ }^{26}$ as the standard deviation of the difference from the mean of repeat measurements divided by the mean response) for the data collected during sessions one and two are 0.016 and 0.019 respectively (the smaller the coefficient of repeatability the more confident one can be regarding the repeatability of the data).

\section{Inter-session reproducibility}

Inter-session reproducibility involves comparing the first set of data with the second set of data collected 24 hrs later. Table 2 provides the mean difference (MD), the $95 \%$ confidence interval for the mean difference, the $95 \%$ limits of agreement (LOA) and the coefficient of reproducibility (COR) for the data collected. The COR is suggested as being the standard deviation of the differences between the pairs of measurements divided by the average of the mean difference of each pair of measurements ${ }^{26}$. 
Table 2. The mean difference (MD) between the two sets of osmolarity data, 95\% limits of agreement (LOA) and the coefficient of reproducibility (COR) are shown. Included is the confidence interval on the MD (CI). The COR has no units while all other metrics have units of $\mathrm{mOsms} / \mathrm{L}$.

\begin{tabular}{c|l|l|l} 
MD & $95 \% \mathrm{CI}$ on MD & $95 \% \mathrm{LOA}$ & $\mathrm{COR}$ \\
\hline 4.1 & $-2.95-11.15$ & $-15.20-23.40$ & 0.029
\end{tabular}

Figure 2 shows a Bland-Altman plot for the data collected during sessions one and two. The mean difference between the two sets of data is indicated by the straight line through the figure and is labelled "Mean". The mean difference is also termed bias and gives an indication whether one set of measurements is consistently lower or higher than the other ${ }^{26}$. The $95 \%$ LOA $( \pm 1.96 \mathrm{SD})$ is indicated by the dotted lines which give insight of how random variation might affect the two sets of measurements. The $x$-axis (average of TLR2 and TLR) is the mean of each two measurements taken during session one and two while the $y$-axis (TLR2 - TLR) is the difference between the sets of measurements taken during sessions one and two.

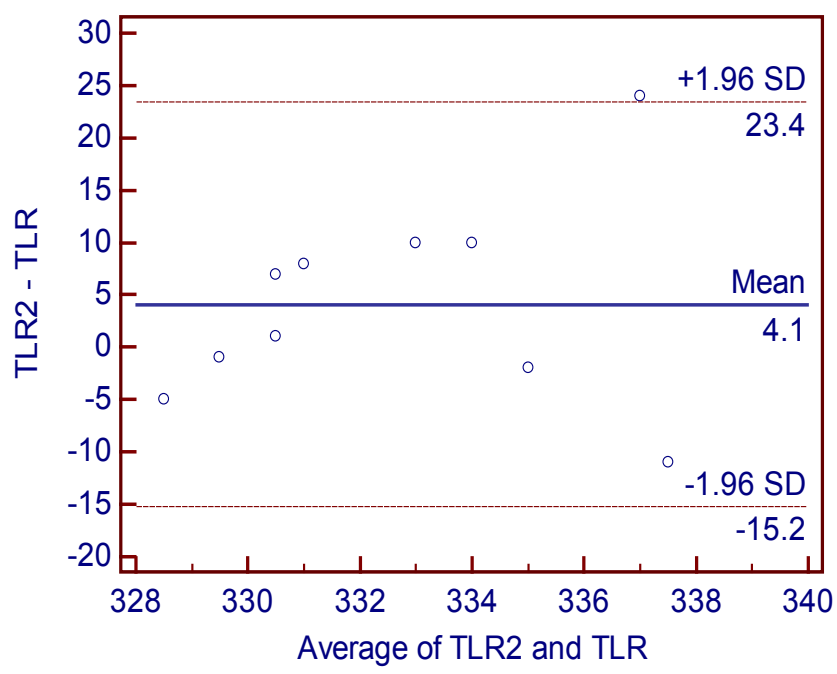

Figure 2. A Bland-Altman plot is shown. The $x$-axis shows the average of pairs of measurements while the $y$-axis shows the difference between pairs of measurements. The mean difference between the two sets of data (MD) is shown by the solid line while the $95 \%$ LOA are shown by dotted lines.

A Kolmogorov-Smirnov test was conducted on the data collected from each session to determine if the data were normally distributed. Both sets of data were found to be normally distributed $(p=0.39$ for session one and $p=0.86$ for session two). To determine whether the mean osmolarity of the first session of measurements was significantly different to the mean osmolarity of the second session of measurements, a paired samples $t$ test $(p=0.22)$ as well as a Wilcoxon paired samples test $(p=0.32)$ was performed on the data. Both tests indicate that there is not enough evidence to reject the null hypothesis, which states that there is no difference between the means determined during sessions one and two at a $95 \%$ level of confidence.

\section{Discussion}

Tear osmolarity is considered to be an important diagnostic indicator of dry eye disease ${ }^{14,15}$. Some authors are of the opinion that tear osmolarity might be the best single metric for the diagnosis of dry eye ${ }^{11,15,17}$, with others stating that tear osmolarity measurements provide an objective indication of improvement in dry eye patients following treatment ${ }^{20}$. The Tearlab osmolarity system was designed to provide a clinically useful measure of the osmolarity of tears ${ }^{16}$. An important requirement for any instrument is to be reliable, repeatable and reproducible with this study investigating these features of the Tearlab system.

The osmolarity of a calibration solution (obtained from Tearlab corporation) was measured ten successive times in an initial measurement session with another ten measurements taken approximately 24 hours later. The mean osmolarity for the ten measurements taken during the two sessions is detailed in Table 1 (included are other descriptive statistics). The osmolarity of the calibration solution was indicated to be $338 \mathrm{mOsmls} / 1$ by the manufacturer. The results of this investigation suggest that the instrument under-estimated the osmolarity of the calibration solution (see Table 1). The expected range from the mean of measurements of the Tearlab system as stated by the manufacturer ${ }^{16}$ is $\pm 15 \mathrm{mOsmls} / 1$ with a standard deviation of $\pm 3 \mathrm{mOsmls} / \mathrm{l}$. The ranges determined for the measurements obtained in this study were $-5.6-12.4$ and $-8.7-14.3 \mathrm{mOsmls} / \mathrm{l}$ for the first and second set of measurements respectively, ranges which are within the manufacturer's specifications. The standard deviations for the data collected, however, were greater than that stated by the manufacturer (see Table 1).

\section{Intra-session measurements}

The coefficients of repeatability (also known as 
the coefficient of variation) for the data collected in sessions one and two are 0.016 and 0.019 respectively. The clinical utility guide, published by Tearlab corporation $^{28}$, states that the coefficient of variation for the Tearlab osmolarity system is approximately $1.5 \%(0.015)$ which compares favourably with the results obtained here. The data collected here suggest that the Tearlab system provides measurements of tear osmolarity that can be considered to be repeatable. Referring to a report published by the College of American Pathologists, Yildiz et $a l^{29}$ provide an indication of different osmometer's performances in terms of coefficients of variation with a mean COV of $1.63 \%$ and $1.72 \%$ for two different test solutions. The Tearlab system thus compares favourably.

\section{Inter-session measurements}

Table 2 gives the results for the inter-session data collected in this study. The mean difference between measurements collected during sessions one and two is $4.1 \mathrm{mOsms} / 1$ (indicating that the second set of measurements were biased, and higher than the first set of measurements, by $4.1 \mathrm{mOsmls} / \mathrm{l})$. The mean difference $(4.1 \mathrm{mOsml} / \mathrm{l})$ between the two sets of measurements could be considered to be small from a clinical point of view. If the two sets of measurements were exactly the same (no bias) the mean difference would be zero. Figure 2 shows a Bland-Altman plot which indicates this mean difference. Also indicated in Figure 2 are the 95\% LOA for the data collected (the LOA are obtained by multiplying the standard deviation by 1.96). The narrower the 95\% LOA the less influence random variation has had on the data. What constitutes a narrow (or wide) LOA is a practical/clinical decision and data dependent. A paired samples $t$-test and a Wilcoxon paired samples test were conducted to investigate whether a significant difference exists between the means of sessions one and two. The results suggest that there is no significant difference between the means at a 95\% level of confidence ( $p=0.22$ and $p=0.32$ respectively). The coefficient of reproducibility is $0.029(2.9 \%)$ which suggests that measurements conducted 24 hours apart are reproducible.

Negative aspects of this study might include: possible outliers exist in the data $(343 \mathrm{mOsms} / 1$ in session one and $349 \mathrm{mOsms} / 1$ in session two, see Table 1). Re-analysis of the data was not conducted once the possible outliers were removed. Had this been done better repeatability and reproducibility might have been indicated. The samples are small and this could have implications for some of the statistical tests that were conducted (the exact influence small sample sizes might have had on certain conclusions made in this study are not clear to me).

\section{Conclusion}

The results of this study suggest that the Tearlab osmolarity system provides reasonably accurate, repeatable and reproducible measurements of tear osmolarity. The system is easy to use, relatively non-invasive and provides quick results allowing clinicians to obtain measurements of tear osmolarity. Considering the potential importance of osmolarity as an indicator of dry eye disease, this instrument could become an important tool in the clinician's armamentarium against this potentially debilitating disease.

\section{Acknowledgements}

The author has no financial or any other interests in Tearlab corporation.

\section{References}

1. Lemp MA (Chair). Definition and classification of dry eye. Report of the diagnosis and classification subcommittee of the international Dry Eye Workshop. Oc Surf 20075 75-92.

2. Gipson IK (Chair). Research in dry eye. Report of the research subcommittee of the international Dry Eye Workshop. Oc Surf 20075 179-193.

3. Doughty MJ, Fonn D, Richter D, Simpson T, Caffery BA, Gordon K. A patient questionnaire approach to estimating the prevalence of dry eye symptoms in patients presenting to optometric practices across Canada. Optom Vis Sci 1997 74 624-631.

4. Moss SE, Klein R, Klein DF. Prevalence of and risk factors for dry eye syndrome. Arch Ophthalmol 2000118 12641268.

5. Schaumberg DA, Sullivan DA, Buring JE, Dana MR. Prevalence of dry eye syndrome among US women. Am J Ophthalmol 2003136 318-326.

6. Bandeen-Roche K, Muñoz B, Teilsch JM, West SK, Schein OD. Self-reported assessment of dry eye in a population based setting. Inv Ophthalmol Vis Sci 199738 2469-2475.

7. Lemp MA. Epidemiology and classification of dry eye. $A d v$ Exp Med Biol 1998438 791-803. 
8. Bron AJ (Chair). Methodologies to diagnose and monitor dry eye disease. Report of the diagnostic methodology subcommittee of the international dry eye workshop. $O c$ Surf 20075 108-152.

9. Narayanan S, Miller WL, Prager TC, Jackson JA, Leach NE, McDermott AM, Christensen MT, Bergmanson JPC. The diagnosis and characteristics of moderate dry eye in non-contact lens wearers. Eye Contact Lens 200531 96104.

10. Begley CG, Chalmers RL, Abetz L, Venkatarama K, Mertzanis P, Caffery BA, Snyder C, Edrington T, Nelson $\mathrm{D}$, Simpson T. The relationship between habitual patient reported symptoms and clinical signs among patients with dry eye of varying severity. Inv Ophthalmol Vis Sci 2003 44 4753-4761.

11. Khanal S, Tomlinson A, McFadyen A, Diaper C, Ramaesh K. Dry eye diagnosis. Inv Ophthalmol Vis Sci 200849 1407-1415.

12. Schein OD, Tielsch JM, Muñoz B, Bandeen-Roche K, West S. Relation between signs and symptoms of dry eye in the elderly: a population based perspective. Ophthalmol 1997104 1395-1401.

13. Mathers WD. Why the eye becomes dry: a cornea and lacrimal gland feedback model. CLAO 200026 159-165.

14. Tomlinson A, Khanal S. Assessment of tear film dynamics: a quantitative approach. Oc Surf 20053 81-95.

15. Tomlinson A, Khanal S, Ramaesh K, Diaper C, McFadyen A. Tear film osmolarity: determination of a referent for dry eye diagnosis. Inv Ophthalmol Vis Sci 200647 4309-4315.

16. Osmolarity system: user manual. Tearlab corporation San Diego, USA.

17. Lemp MA, Bron AJ, Baudouin C, Benítez Del Castillo JM, Geffen D, Tauber J, Foulks GN, Pepose JS, Sullivan BD. Tear osmolarity in the diagnosis and management of dry eye disease. Am J Ophthalmol 2011 151 792-798.

18. Montani G. Tear film osmolarity changes with different eye drops. Contact Lens Ant Eye 201134 (supplement) S18.

19. Peral A, Dominguez-Godinez C, Corracedo G, MartinezFlorentin G. Effect of contact lens wear on tear osmolarity in a normal population. Contact Lens Ant Eye 201134 (supplement) S18.

20. Benelli U, Nardi M, Posarelli C, Albert TG. Tear osmolarity measurement using the Tearlab osmolarity system in the assessment of dry eye treatment. Contact Lens Ant Eye 201033 61-67.

21. Taylor BW, Kuyatt CE. Guidelines for evaluating and expressing the uncertainty of NIST measurements and results. NIST technical note 1297, United States Department of Commerce Technology Administration, 1994.

22. Murray A, Lawrence GP. How should the repeatability of clinical measurements be analyzed? An assessment of analysis techniques with data from cardiovascular autonomic tests. Quarterly Med Jnl 199386 831-836.

23. Moreno-Montañés J, Maldonado MJ, García N, Mendiluce L, García-Gómez PJ, Sequí-Gómez M. Reproducibility and clinical relevance of the Ocular Response Analyzer in non-operated eyes: corneal biomechanical and tonometric implications. Inv Ophthalmol Vis Sci 200849 968-974.

24. Muscat S, McKay N, Parks S, Kemp E, Keating D. Repeatability and reproducibility of corneal thickness measurements by optical coherence tomography. Inv Ophthalmol Vis Sci 200243 1791-1795.

25. Muscat S, Parks S, Kemp E, Keating D. Repeatability and reproducibility of macular thickness measurements with the Humphrey OCT system. Inv Ophthalmol Vis Sci 200243 490-495.

26. Bland JM, Altman DG. Statistical methods for assessing agreement between two methods of clinical measurement. Lancet 19868 307-310.

27. Julio G, Lluch S, Pujol P, Merindano MD. Effects of hyperosmolarity on conjunctival cells in mild to moderate dry eye. Ophthal Physiol Opt 201232 317-323.

28. Tearlab osmolarity system: clinical utility guide. Tearlab corporation, San Diego USA.

29. Ylidiz EH, Fan VC, Banday H, Ramanathan L, Bitra RK, Garry E, Asbell PA. Evaluation of a new tear osmometer for repeatability and accuracy, using $0.5 \mu \mathrm{l}$ (500 nanoliters) samples. Cornea 200928 677-680. 